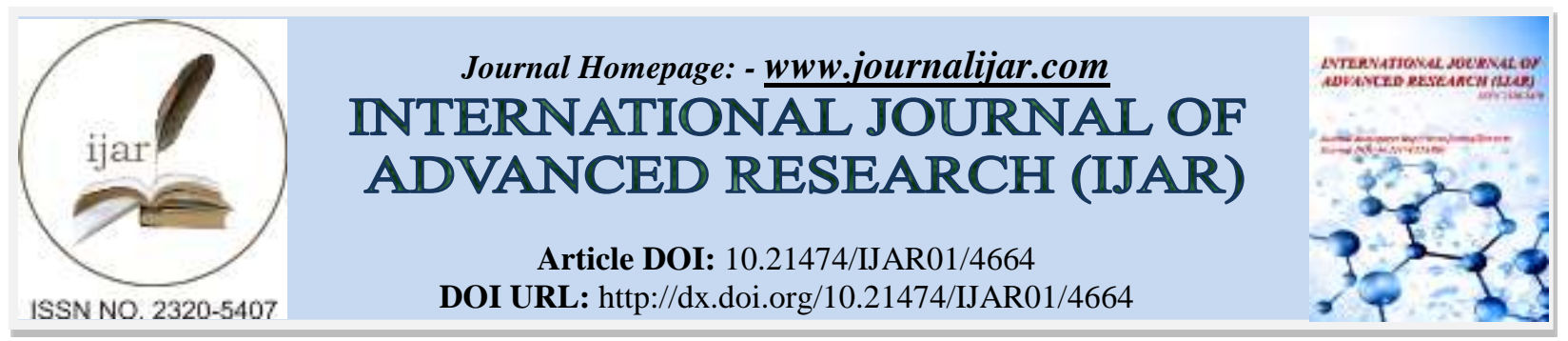

RESEARCH ARTICLE

\title{
EFFECT OF STATIC MAGNETIC FIELD ON PROTEASE PRODUCED BY FIVE FUNGAL ISOLATES USING SOLID STATE FERMENTATION.
}

Abdulwahid Shamki Jabir and Marow Sabah

University of Al-Nahrain, college of biotechnology - Baghdad Iraq.

\section{Manuscript Info}

Manuscript History

Received:24 April 2017

Final Accepted: 29 May 2017

Published: June 2017

Key words:-

Protease, Amylase, magnetic field

\section{Abstract}

In this study, the effect of static magnetic field on the production of protease enzymes using solid state fermentations from five different fungal species Alternaria sp., Aspergillus niger, Fusarium sp., Mucor $s p$., and Penicillium $s p$. were investigated. The substrate used for fungi growth was bread only. The above species were exposed to the Northern pole, Southern pole and both poles together (South + North) and their effects were compared with the control treatment (The control of all experiments was the solid medium without the effect of the magnetic field). The results were statistically analyzed by GenStat Programm and the Least Significant Differences (LSD) was determined. The results showed that the effect of the magnetic field of the protease specific activity, Northern pole significantly decreased the protease specific activity of Alternaria sp., Aspergillus niger, and Penicillium sp., which were $16.86,14.69,12.03 \mathrm{U} / \mathrm{mg}$ respectively. The Southern pole significantly increased the protease specific activity of Fusarium sp. (23.04 U/mg) and Mucor sp. (12.15 U/mg) except Alternaria $s p$. in which its protease specific activity was decreased significantly $(19.30 \mathrm{U} / \mathrm{mg})$. Both poles significantly increased protease specific activity of Fusarium sp. (21.03 U/mg) and Mucor sp. $(9.75 \mathrm{U} / \mathrm{mg})$, whereas they significantly decreased protease specific activity of Alternaria sp. (13.65 U/mg) and Penicillium sp., (8.19 $\mathrm{U} / \mathrm{mg}$ ). This study clearly showed that there is a significant effect of the electrostatic, magnetic field in increasing and decreasing the enzymes activities of the fungal species which could be exploited industrially in increasing the production of important enzymes in industry such as proteases.

Copy Right, IJAR, 2017,. All rights reserved.

\section{Introduction:-}

Mycology is a term derived from a Greek word myke means „,mushroom ${ }^{e e}$, and logos mean ,study ${ }^{e e}$. So, mycology is the study of mushrooms. However, mycology is commonly used to refer to the study of organisms called fungi. Fungi are found in two structural forms. One of them yeast cells, which are unicellular. The other is hyphae which made up of thread like structures. A group of hyphae are known as mycelium. Outer cell wall of Fungi are typically made up of a porous, made up of chitin. Inner to the cell wall is a cell membrane that is wrapped up in places to increase its surface area for exchange of materials. Heterotrophs can either be saprobes, symbionts or parasites. 
Reproduction occurs both sexual and asexual means. Fungi are important in the food industry. In many counties, mushrooms which considered a delicacy at the dining table. Species such as Penicillium sp. are used to add flavour to the cheese. The yeasts are important in the fermentation processes of wine and beer manufacturing. Fungi are important in the breakdown of organic matter and organic wastes, it is useful in cleaning up of wastes in an ecosystem and contribute to the recycling of nutrients. Some of fungi cause various diseases in plants, but only a few species cause disease in animals and humans, these diseases are permanent (Alexopoulos et al., 1996). The history of magnetic materials development cannot be denied and it is fabulous. Magnetic objects played an important role in the discovery of the new world and in the development of modern technology. The magnetic properties of materials are important to understand them, which led to a deep understanding the main structure of materials. One of the basic properties of materials is magnetizing; these materials appear in different forms, but the studied form known as ferromagnetism. Magnetic field only refers to the elements that exhibit ferromagnetism properties. A magnet is an object that has a magnetic field. "Magnítis líthos", is a Greek word mean magnet which means "magnesian stone". Magnetite has been discovered in Magnesia, which is an area in Greece, where Magnetite deposits (Peter et al., 2002). For a long time period the effect of magnetic field on biological systems has been an area of interest. Unlike time-varying (electromagnetic) field, which are not related to induced electric currents except during activation and deactivation or when there is motion within the magnetic field. It is effected on the molecular structure of spasmodic membranes, an influence sufficient to alter the role of embedded ion-specific channels. The effect of the magnetic field energy causes significant changes in the characteristic metabolism of organisms; these changes occur in the exchange of ions through the cell membrane and in the movement of cells. Magnetic field (MF) and electromagnetic field (EMF) that are generated from both external MF and EMF and internal sources natural metabolisms of organisms effect on biological systems. Depending on several studies, magnetic and electromagnetic fields have various responses for Biosystems such as neuromuscular activity, repair and tissue growth, glandular secretion, and cell membrane function. Electromagnetic field has an effect mostly on charges units and related metabolisms and usually has an influence on biochemical reactions that include more than one unpaired electron. The impact of an external magnetic field on enzymatic reaction rates can be determined in the same way classical enzyme kinetic parameters are determined. Enzymes with chromogenic substrates or products can be followed spectrophotometrically (Koch et al., 2003). The purpose of the study was to: Investigate the effect of static magnetic field on amylase and protease production using solid state fermentation.

\section{Materials And Methods:-}

Fungal species: The fungi species, Penicillium sp., Alternaria sp., Fusarium sp., Mucor sp., and Aspergillus niger were obtained from the Department of Biology/ College of Science/ University of Baghdad. The fungi species were identified after growing on Potato Dextrose Agar (PDA) medium by observing the growth characteristics (color, texture, appearance and diameter of colonies) and microscopic (microstructure).( Bissett, J. 1991) (Baijal, U. and Mehrotra, B.S, 1980.) All the cultures were maintained on PDA slants. Then, stored in refrigerator and sub-cultured regularly at an interval of three months.

Static magnetic field: A special magnetic bar of thickness $(2.9 \mathrm{~cm})$ with single field strength of 100 Gauss which was measured by a Gauss meter. The magnetic bars (North Pole, South Pole, or both poles) were put on the side of the cultured flasks using adhesive tape.

\section{Spores' suspension preparation:-}

Spores' suspension was prepared according to (Faraj, M.K. 1990) with slight modifications as follows:

$\square$ Plates containing PDA medium inoculated with fungal isolates were incubated at $28^{\circ} \mathrm{C}$ for $3-4$ days.

$\checkmark$ Spores were harvested by adding $5 \mathrm{ml}$ of DW on the plate.

$\square$ The spore suspension was transferred by a micropipette to a flask containing sterilized bread and incubated at 28

${ }^{\circ} \mathrm{C}$ for 5 days.

$\square$ One hundred $\mathrm{ml}$ of DW was added to the flask and mixed vigorously by hand.

$\square$ The suspension of spores was filtered through sterile cotton wool.

$\square$ The suspension was centrifuged at (3000 rpm for $5 \mathrm{~min}$ ). Then, the supernatant was discarded and the spores then washed twice by DW and further re-centrifuged.

$\square$ Then, $1 \mathrm{ml}$ of DW was added to the deposit and mixed vigorously.

The following equation was used to estimate the number of spores $/ \mathrm{ml}$ in original suspension: Spores $/ \mathrm{ml}=$ (Average no. of spores / 5) $\times(25) \times(104) \times$ (Dilution Factor).

To test the effect of the magnetic field on the fungi cultures under solid state fermentation the following steps were carried out 
$\square$ Bread loaves were cut into pieces (approximately $1 \mathrm{~cm} 3$ ) using a bread loaf knife.

$\square$ Twelve culture flasks were loaded with $30 \mathrm{~g}$ of bread pieces and autoclaved at $121^{\circ} \mathrm{C}$ for $15 \mathrm{~min}$.

$\square$ Each flask was inoculated with 108 spores/ml of fungus.

$\checkmark$ The twelve flasks were divided into four groups as follows

Three flasks used as control, three flasks were put under the effect of northern pole, three flasks were put under the effect of southern pole and three flasks were put under the effect of both poles.

$\square$ The flasks were incubated at $28{ }^{\circ} \mathrm{C}$ for 7 days with shaking every day.

\section{Crude enzyme extraction:-}

After 7 days of fungal fermentation, extraction of crude enzyme was done as follows

$\square$ To each culture flask, $100 \mathrm{ml}$ of phosphate buffer $(\mathrm{pH} \mathrm{7)}$ was added and shake vigorously to suspend the bread pieces.

$\square$ The whole content of the flask was filtered through sterile cotton wool and centrifuged at (3000 rpm for $5 \mathrm{~min}$ ).

$\square$ The supernatant was assembled and filtered by filter paper Whatman No.1 under vacuum.

$\square$ The filtrate was stored at $4{ }^{\circ} \mathrm{C}$.

Determination of protein concentration by Bradford method (1976):-

The concentration of protein was determined by using the Bradford method, as follows:

$\square$ The Bradford reagent was gently mixed and brought to room temperature.

$\square$ A protein standard was prepared ranging from $(0.2$ to $1 \mathrm{mg} / \mathrm{ml})$. Dilutions are given in Table (2-3) below. Each concentration was done in triplicate.

$\square$ The unknown samples were prepared in a similar way to make the final volume $(0.1 \mathrm{ml})$.

$\square$ To all the tubes, $(3.0 \mathrm{ml})$ of Bradford reagent were added with continuous mixing, then incubated at room temperature for $5 \mathrm{~min}$.

$\square$ The absorbance was measured at $595 \mathrm{~nm}$ using spectrophotometer

Table 1:- Preparation of Bovine serum albumin standard curve.

\begin{tabular}{|c|c|c|c|}
\hline $\begin{array}{c}\text { BSA standard } \\
(\mu \mathrm{l})\end{array}$ & $\begin{array}{c}\text { Dilution buffer } \\
(\mu \mathrm{l})\end{array}$ & $\begin{array}{c}\text { Final concentration } \\
(\mathrm{mg} / \mathrm{ml})\end{array}$ & Absorbance $(595 \mathrm{~nm}$ \\
\hline 10 & 90 & 0.2 & 0.238 \\
\hline 20 & 80 & 0.4 & 0.410 \\
\hline 30 & 70 & 0.6 & 0.568 \\
\hline 40 & 60 & 0.8 & 0.750 \\
\hline 50 & 50 & 1.0 & 0.921 \\
\hline
\end{tabular}

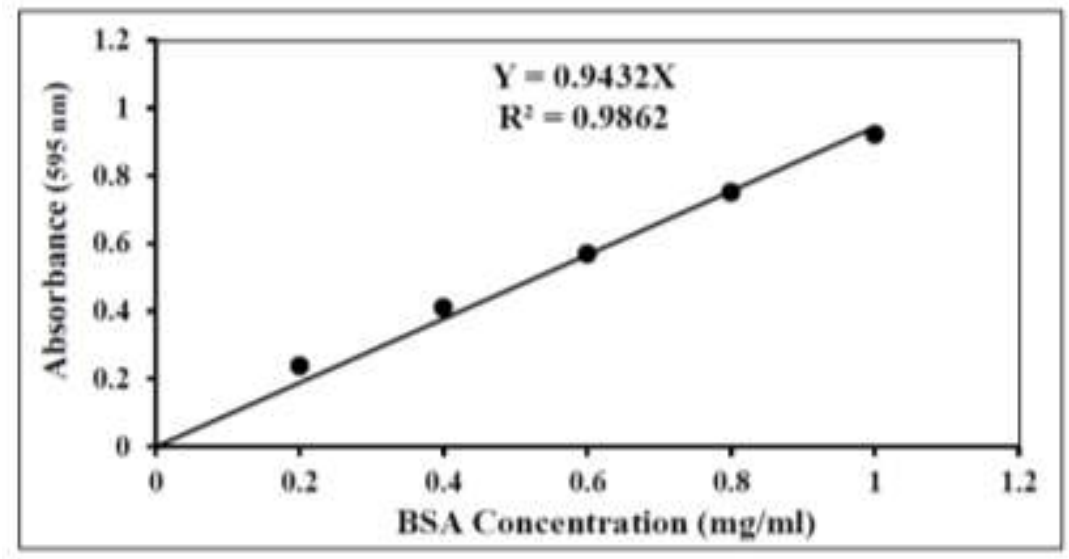

Figure 1:- Bovine serum albumin standard curve.

\section{Preparation of tyrosine standard curve:-}

The tyrosine standard curve was prepared as follows:-

$\square$ From the tyrosine stock solution, five concentrations, ranging from (0.055 to $0.553 \mu \mathrm{Mole})$ were prepared. Each concentration was done in triplicate. A test tube containing a blank solution was also prepared. 
$\square$ The volume was brought up to $(2 \mathrm{ml})$ in each test tube, including the test tube by DW containing the blank solution.

$\square$ In each tube, $(5 \mathrm{ml})$ of sodium carbonate were added to regulate any $\mathrm{pH}$ drop due to the addition of the Folin's reagent.

$\square$ One $\mathrm{ml}$ of Folin's reagent was added immediately. The tubes were mixed by swirling and incubated at $37{ }^{\circ} \mathrm{C}$ for $30 \mathrm{~min}$, blue color is developed.

$\square$ The absorbance of our samples was measured by a spectrophotometer at $660 \mathrm{~nm}$.

$\square$ A graph with the concentration of tyrosine on $\mathrm{X}$ axis against absorbance at $660 \mathrm{~nm}$ on $\mathrm{Y}$ axis was plotted.

Table 2:- preparation of tyrosine standard curve.

\begin{tabular}{|c|c|c|c|}
\hline $\begin{array}{c}\text { Tyrosine standard } \\
(\mathrm{ml})\end{array}$ & $\mathrm{DW}(\mathrm{ml})$ & $\begin{array}{c}\text { Tyrosine } \\
\text { Final concentration } \\
(\mu \mathrm{mol} / \mathrm{ml})\end{array}$ & $\begin{array}{c}\text { Absorbance } \\
(660 \mathrm{~nm})\end{array}$ \\
\hline 0.05 & 1.95 & 0.0275 & 0.050 \\
\hline 0.1 & 1.9 & 0.055 & 0.124 \\
\hline 0.2 & 1.8 & 0.110 & 0.277 \\
\hline 0.4 & 1.6 & 0.220 & 0.603 \\
\hline 0.5 & 1.5 & 0.275 & 0.736 \\
\hline
\end{tabular}

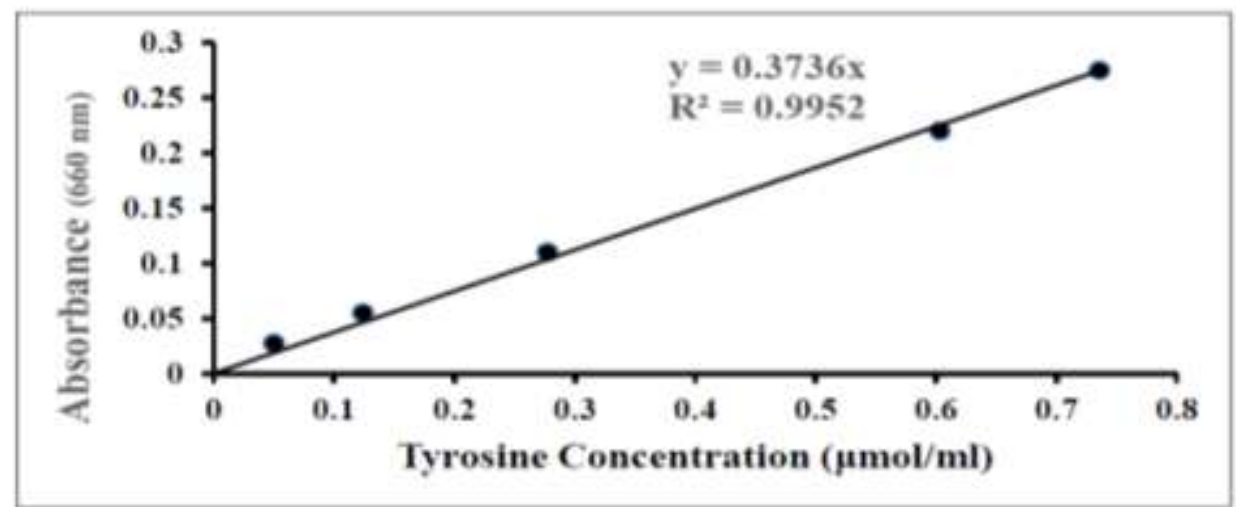

Figure 2:- Tyrosine standard curve for protease activity.

\section{Assay of Protease activity:-}

The activity of protease was assayed using casein as a substrate according (Anson, 1938):

$\square$ Thirteen sterile test tubes were prepared. One tube was used as a blank and the others were used to assay the activity of protease $\square$ In each tube, $(5 \mathrm{ml})$ of $0.65 \%$ casein solution was added and these tubes were placed in a water bath at $37^{\circ} \mathrm{C}$ for about $5 \mathrm{~min}$.

$\square$ In each tube, $(1 \mathrm{ml})$ of the enzyme extract was added, except the blank in which $1 \mathrm{ml}$ of $\mathrm{DW}$ was added, mixed by swirling and incubated at $37^{\circ} \mathrm{C}$ for exactly $10 \mathrm{~min}$. $\square$ Five milliliters of TCA reagent were added in each tube to stop the reaction and incubated at $37^{\circ} \mathrm{C}$ for $30 \mathrm{~min}$.

$\square$ In each tube, $(5 \mathrm{ml}$ ) of sodium carbonate were added to regulate any $\mathrm{pH}$ drop created by the addition of the Folin's reagent.

$\square$ One $\mathrm{ml}$ of Folin's reagent was added immediately. The tubes were mixed by swirling and incubated at $37{ }^{\circ} \mathrm{C}$ for $30 \mathrm{~min}$, Folin's reagent reacts with protein to produce a blue color.

$\square$ The absorbance was measured by a spectrophotometer at $660 \mathrm{~nm}$.

\section{Protease specific activity (U/mg)}

$\square$ Absorbance values obtained from protease activity were put in the standard curve equation (Figure 2-1) to get the amount of tyrosine in micromoles.

$\square$ From the values generated above, the total activity of protease samples can be calculated in terms of Units, which is the amount of tyrosine released from casein in micromoles per minute, according to the following equation:

Protease activity $($ Units $/ \mathrm{ml})=$

( Umol / mol of tyrosine release) X 11

(1) X (10) 
Where:

$11=$ Assay total volume $(\mathrm{ml})$

$\square 1=$ Volume of enzyme used $(\mathrm{ml})$

$\square 10=$ Assay time (min) as the Unit definition

$\square$ Finally the enzyme specific activity was estimated by dividing the enzyme activity on the protein activity obtained from bovine serum albumin standard curve (Figure 2-1) according to the following equation:

$\begin{aligned} \text { Protease specific activity }(\mathrm{U} / \mathrm{mg})= & \text {------------------------------ } \\ & (\text { Protein concentration } \mathrm{mg} / \mathrm{ml} \text { ) }\end{aligned}$

\section{Results and Discussion:-}

Effect of Magnetic Field on the Protease Specific Activity

Effect of Magnetic Field on the Protease Specific Activity of Alternaria sp.

The effect of magnetic field on the specific activity of protease of Alternaria sp. was tested. After 7 days of fermentation on solid medium (bread cubes) at $28{ }^{\circ} \mathrm{C}$. The LSD of this experiment was (2.644). All treatments significantly decreased the protease specific activity (Figure 3). The Northern and Southern Poles as well as the two poles together (South + North) specific activities were $(16.86 \mathrm{U} / \mathrm{mg}),(19.30 \mathrm{U} / \mathrm{mg})$, and $(13.65 \mathrm{U} / \mathrm{mg})$ respectively when compared to the Control $(24.05 \mathrm{U} / \mathrm{mg})$.

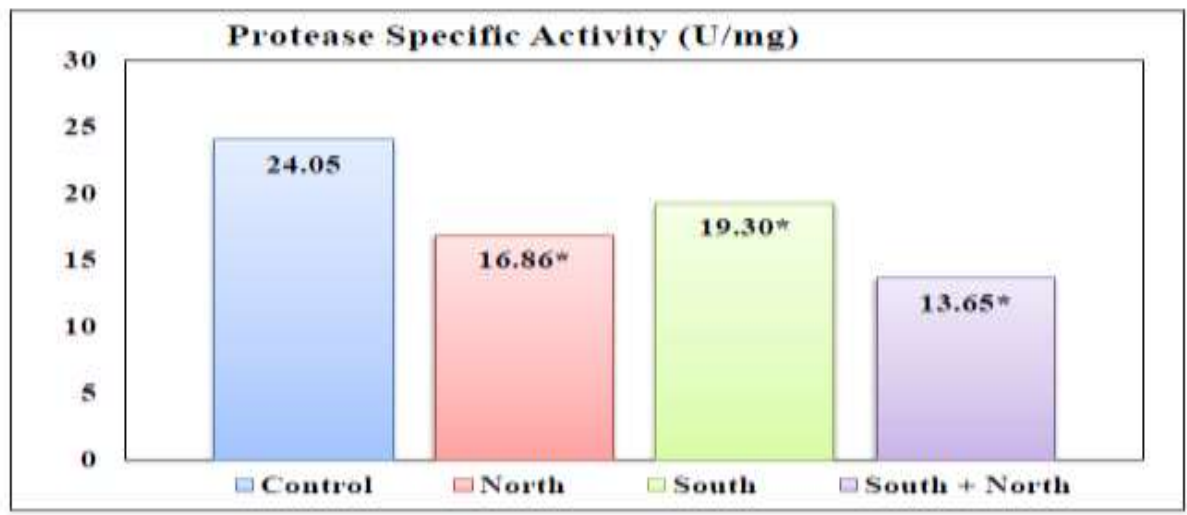

Figure 3: - effect of msgneti field of protease specific activity of Alternaria sp

Figure 4).The effect of magnetic field on the specific activity of protease of Aspergillus niger was studied after 7 days of fermentation on solid medium (bread cubes) at $28{ }^{\circ} \mathrm{C}$. The LSD of this experiment was (2.932). The study showed that the specific activity of the Control was $(20.15 \mathrm{U} / \mathrm{mg}$ ) (without MF), the Northern Pole significantly decreased specific activity $(14.69 \mathrm{U} / \mathrm{mg}$ ). The two poles together (South + North) nonsignificantly decreased the specific activity $(19.16 \mathrm{U} / \mathrm{mg})$. On the other hand, the Southern Pole increased specific activity $(21.35 \mathrm{U} / \mathrm{mg})$, however, the increase was non-significant (Figure 4).

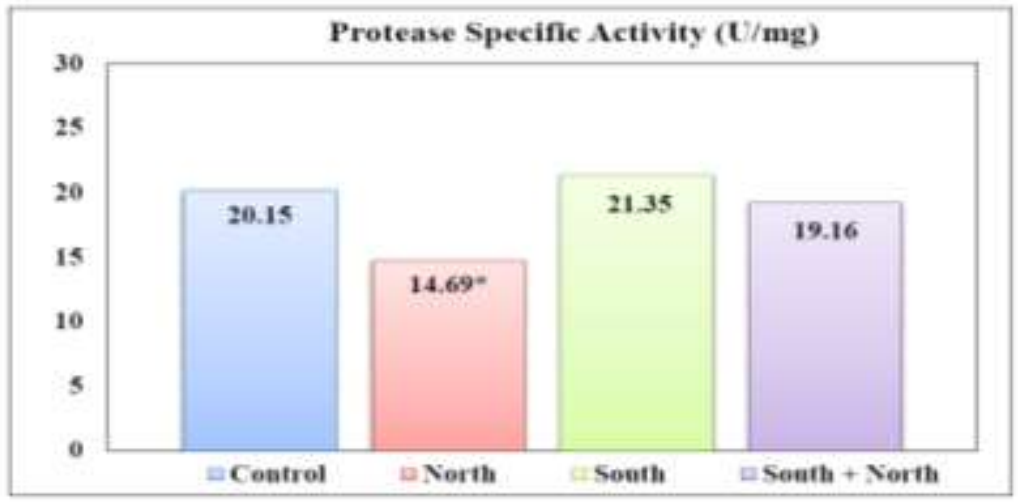

Figure 4:- The effect of magnetic field on the specific activity of protease of Aspergillus niger 


\section{Effect of Magnetic Field on the Protease Specific Activity of Fusarium sp:-}

The effect of magnetic field on specific activity of protease of Fusarium sp. was studied. The results after 7 days of fermentation on solid medium (bread cubes) at $28{ }^{\circ} \mathrm{C}$ indicated that the Control specific activity was $(10.70 \mathrm{U} / \mathrm{mg})$. The LSD of this experiment was (3.478). The Southern Pole significantly increased specific activity $(23.04 \mathrm{U} / \mathrm{mg})$ as well as the two poles together (South + North) $(21.03 \mathrm{U} / \mathrm{mg})$. The Northern Pole non- significantly decreased specific activity $(10.21 \mathrm{U} / \mathrm{mg})$ (Figure 5).

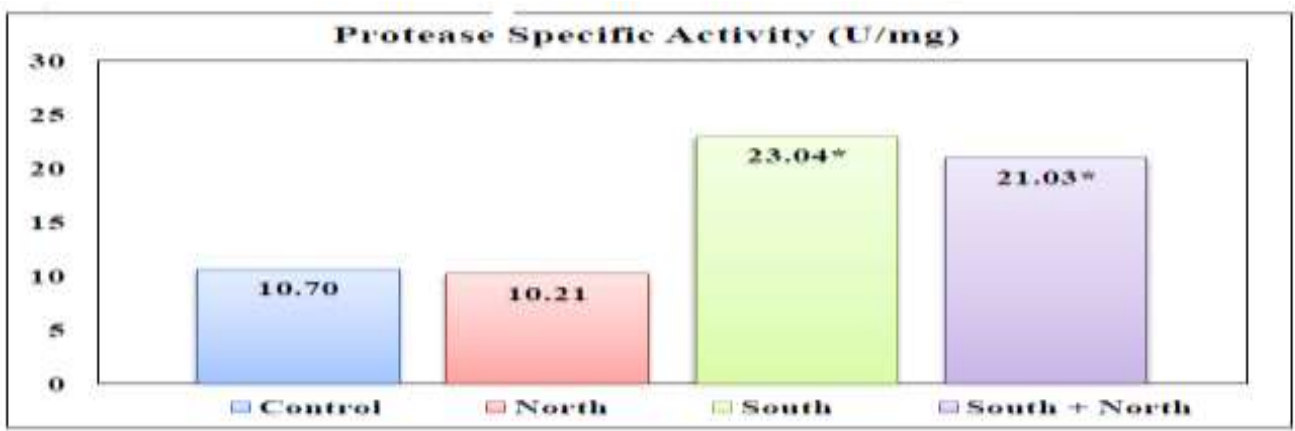

Figure 5:- The effect of magnetic field on specific activity of protease of Fusarium sp

\section{Effect of Magnetic Field on the Protease Specific Activity of Mucor sp:-}

The effect of magnetic field on specific activity of protease of Mucor sp. was measured. After 7 days of fermentation on solid medium (bread cubes) at $28{ }^{\circ} \mathrm{C}$, the results displayed that the specific activity of the Control was $(6.06 \mathrm{U} / \mathrm{mg})$. The LSD of this trial was (2.424). As seen in the Figure (6), the Southern Pole significantly increased specific activity $(12.15 \mathrm{U} / \mathrm{mg}$ ) as well as the two poles together (South + North) $(9.75 \mathrm{U} / \mathrm{mg}$ ), while the Northern Pole non-significantly decreased specific activity $(5.16 / \mathrm{mg})$.

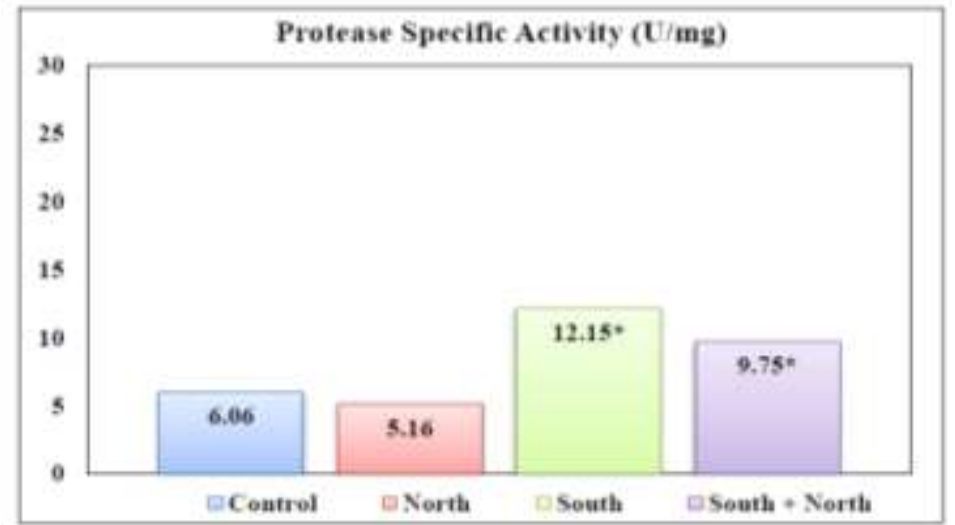

Figure 6:- The effect of magnetic field on specific activity of protease of Mucor $s p$

\section{Effect of Magnetic Field on the Protease Specific Activity of Penicillium sp:-}

The effect of magnetic field on protease specific activity of Penicillium sp. has been investigated. The Figure (7) represent after 7 days of fermentation on solid medium (bread cubes) at $28{ }^{\circ} \mathrm{C}$ that the Control specific activity was $(14.84 \mathrm{U} / \mathrm{mg})$. The LSD of this test was (2.684). The Northern Pole significantly decreased the specific activity $(12.03 \mathrm{U} / \mathrm{mg})$ as well as the two poles together (South + North) $(8.19 \mathrm{U} / \mathrm{mg})$. On ontrary, the Southern Pole nonsignificantly increased the specific activity $(16.04 \mathrm{U} / \mathrm{mg})$. 


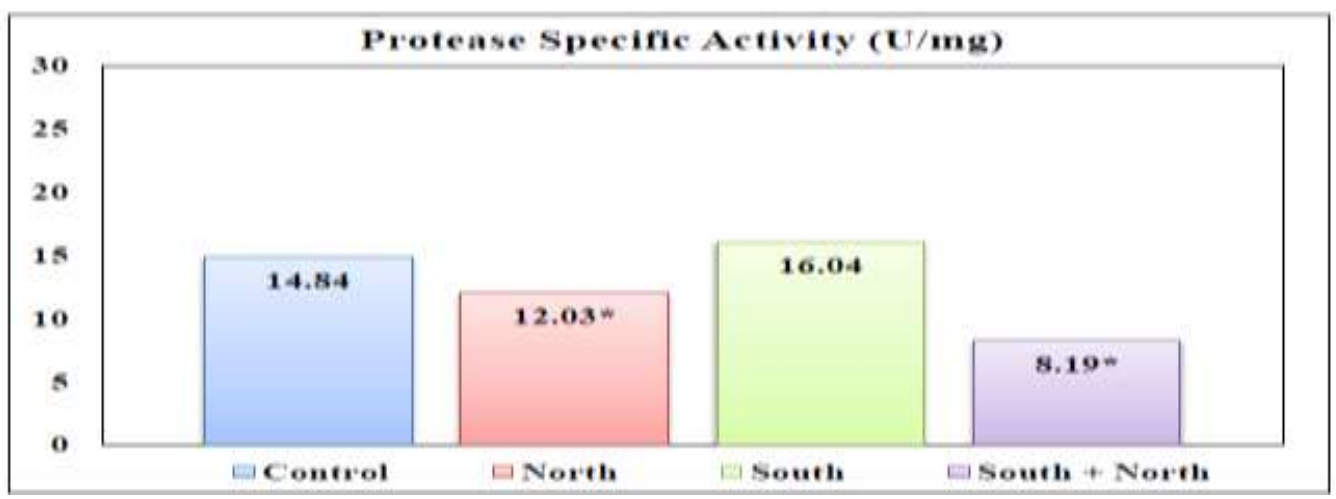

Figure 7:- The effect of magnetic field on protease specific activity of Penicillium $s p$

The statistical analysis of the results in Figures (2,3,4,5and 6)) showed that the Southern Pole treatment significantly increased the protease specific activity of Fusarium sp. And Mucor sp., while it significantly decreases protease specific activity of Alternaria $s p$. Both Poles treatments significantly increased protease specific activity of Fusarium sp., Mucor sp. Whereas decreasing protease specific activity of Alternaria sp. and Penicillium sp. The Northern Pole significantly decreased the protease specific activity of Alternaria sp., Aspergillus niger, and Penicillium sp. Regarding the Southern pole magnetic field effect on protease specific activity, it is logical to expect the increase effect of the enzyme activity due to the probable potentiation of the positivity of cations. However, it is not easy to explain the peculiar decrease of protease activity in the case of the fungus Alternaria sp. The most reasonable explanation of the decrease of enzyme specific activity (protease) after exposing the fungi to the Northern the magnetic field is attributable to the probable interface of the negative charge of magnetic field with the release of the stimulating effect of $(\mathrm{Ca} 2+)$. Blank and Soo (2001), demonstrated the EMF interaction mechanism with Na+- K+ ATPase and suggested to be due to acceleration of the electron, regardless of the direction the electrons move regularly and the threshold force producing the effect on the enzyme. Therefore, it is very likely that the influence of the field on the acid phosphatase could include electron density at the anti-ferromagnetically coupled binuclear Fe(III)-Mn(II) center and the active site. A second theory concluded that the effect of SMF and OMF of calcium ions bound in calcium-binding proteins, like calmodulin. The calcium ions always vibrate about an equilibrium position in the calmodulin binding site. A static magnetic field to calmodulin causes the level of vibration to rotate, or forward in the direction of the magnetic field at a frequency that equal to the cyclotron frequency of the bound calcium. Adding a "wobbling" MF at the cyclotron frequency disturbs the accuracy to such an extent that it loosens the bond between the calmodulin and the calcium ion (Pothakamury et al., 1993).

The ELF EMF influence enzyme activity irrespective of temperature, $\mathrm{pH}$ and substrate concentration. Optimal $\mathrm{pH}$ and temperature are very important for the activity of enzymes. Changing in $\mathrm{pH}$ and temperature affect the shape of an enzyme and change the charge or shape properties of the substrate so that the substrate cannot bind to the active site or undergo catalysis. The stud is searching for whether ELF EMF cause specific changes in the optimal $\mathrm{pH}$ and optimal temperature. However, when the samples were exposed to EMF at various $\mathrm{pH}$ and temperature the OD value was changed, which indicates there was a change in the activity of the enzyme. But there was no significant effect of ELF EMF on optimal pH and temperature (Prashanth et al., 2008).

\section{Conclusions:-}

$\square$ Magnetic field poles (100 gauss) showed different effects on protease specific activity produced from Alternaria sp., Aspergillus niger, Fusarium sp., Mucor sp., and Penicillium sp.

$\square$ The Northern pole had a negative effect on the amylase specific activity of Alternaria sp., Fusarium sp., and Penicillium sp. as well as in the protease specific activity of Alternaria sp., Aspergillus niger, and Penicillium sp.

$\square$ The Southern pole had a positive effect on the protease specific activity of Fusarium sp., and Mucor sp. While it had a negative effect on amylase specific activity of Alternaria sp. and Penicillium $s p$. and protease specific activity of Alternaria sp. as compared with the Control under the same conditions.

$\square$ The two poles together (South + North) showed negative effects on the protease specific activity of Alternaria sp. and Penicillium $s p$. While they showed positive effects on the protease specific activity of Fusarium $s p$. and Mucor $s p$. as compared with the Control under the same conditions. 


\section{References:-}

1. Alexopoulos, C.J., Mims, C.M. and Blackwell, M. (1996). Introductory Mycology (4th Ed.). John Wiley and Sons Inc., New York.

2. Anson, M.L. (1938). J. Gen. Physiol; 22: 79-89.

3. Baijal, U. and Mehrotra, B.S. The genus Cunninghamella sp. a reassessment. Sydowia, 1980; 33: 1-13.

4. Bissett, J. A revision of the genus Trichoderma sp. III section Pachybasium, Can. J. Bot., 1991; 69: 2373-2420

5. Blank, M. and Soo, L. (2001). Electromagnetic acceleration of electron transfer reactions. J. Cell. Biochem., 81: $278-283$.

6. .Bradford, M.M. (1976). A rapid and sensitive method for the quantification of microorganism quantities of protein utilizing the principle of protein _ dye binding. Anal. Biochem., 72: 248-254.

7. Faraj, M.K. Regulation of mycotoxins formation in Zea mays. Ph.D. thesis. Department of Bioscience and Biotechnology, University of Strathclyde, Glascow, U.K, 1990; 117.

8. Koch, B., Sommarin, M., Persson, B., Salford, L.G. and Eberhardt, J.L. (2003). Interaction between week low frequency magnetic fields ans cell membranes. Bioelectromagnetics, 24: 395-402.

9. Peter, H. Wald and Greg M. Stave, (2002). Physical and Biological Agents of the Workplace, (2nd Ed.). New York: John Wiley and Sons.

10. Pothakamury, U.R., Barbosa-Cánovas, G.V., and Swanson, B.G. (1993). Magnetic-field inactivation of microorganisms and generation of biological changes. Food Technol., 47(12): 85-93. 